\title{
Introduction of iodised salt benefits infants' mental development in a community-based cluster-randomised effectiveness trial in Ethiopia
}

\author{
Karim Bougma ${ }^{1 *}$, Frances E. Aboud ${ }^{2}$, Tizita M. Lemma ${ }^{3}$, Edward A. Frongillo ${ }^{4}$ and Grace S. Marquis ${ }^{1}$ \\ ${ }^{1}$ School of Human Nutrition, McGill University, 21111 Lakeshore Road, CINE Building, Sainte Anne-de-Bellevue, QC, H9X \\ 3V9, Canada \\ ${ }^{2}$ Department of Psychology, McGill University, 2001 McGill College Avenue, Montreal, QC, H3A 1G1, Canada \\ ${ }^{3}$ Department of Psychology, Babir Dar University, PO Box 79, Bahir Dar, Ethiopia \\ ${ }^{4}$ Department of Health Promotion, Education, and Behavior, University of South Carolina, Discovery I, 915 Greene Street, \\ Columbia, SC 29208, USA
}

(Submitted 1 March 2017 - Final revision received 29 October 2017 - Accepted 8 December 2017)

\section{Abstract}

The effectiveness of salt iodisation in improving the mental development of young children has not been assessed. We implemented a community-based cluster-randomised effectiveness trial in sixty randomly selected districts in the Amhara region of Ethiopia. We randomly allocated each district to treatment and randomly selected one of its villages. In parallel to national salt iodisation efforts, iodised salt was brought early into the markets of the thirty intervention villages before it became widely available in the thirty control villages $4-6$ months later. The primary outcome was children's mental development scores on the Bayley Scales. This was an intention-to-treat analysis using mixed linear models adjusted for covariates and clusters. The trial was registered at ClinicalTrials.gov, NCT013496. We assessed 1835 infants aged 5-11 months at baseline. The same children ( $85 \%$ of the sample) were re-assessed at 20-29 months when all villages had iodised salt. At endline, urinary iodine concentration was higher in children in the intervention group compared with those in the control group (median $228.0 v \cdot 155 \cdot 1 \mu \mathrm{g} / \mathrm{l}, P=0 \cdot 001)$. The intervention group had higher scores compared with the control group on the Bayley composite score (raw scores: $130 \cdot 60 v .128 .51$; standardised scores: $27 \cdot 8 v .26 \cdot 9 ; d=0 \cdot 13 ; 95 \%$ CI $0 \cdot 02,0.23)$ and three of the four subscales: cognitive (53.27 $v$. $52 \cdot 54, d=0 \cdot 13 ; 95 \%$ CI $0 \cdot 03,0 \cdot 23)$, receptive language $(20 \cdot 71 v .20 \cdot 18, d=0 \cdot 13 ; 95 \%$ CI 0.03, 0.24) and fine motor $(35 \cdot 45 v .34 \cdot 94, d=0 \cdot 15$; $95 \%$ CI $0 \cdot 04,0 \cdot 25)$. The introduction of iodised salt contributes to children's higher urinary iodine concentration and mental development.

\section{Key words: Iodine: Children: Bayley Scales: Cognitive: Language: Fine motor: Maternal depression}

About $43 \%$ of children under 5 years of age in low- and middleincome countries do not reach their full developmental potential mainly because of inadequate psychosocial stimulation and nutritional deficiencies including iodine deficiency ${ }^{(1)}$. Iodine is required for the production of thyroid hormones, which are involved in brain development during fetal life and early infancy ${ }^{(2,3)}$. The consequences of iodine deficiency are said to include delayed motor and mental development, with cretinism being the most extreme form ${ }^{(4)}$.

Evidence for the effects of iodine on mental development comes mainly from children whose pregnant mothers were supplemented and from studies with school-aged children. A recent meta-analysis on the former that focused on development outcomes of children under 5 years of age found medium effect sizes of 0.48 for randomised controlled trials (RCT) and 0.46 for non-RCT ${ }^{(5)}$. The two RCT supplemented pregnant women with iodised oil capsules ${ }^{(6,7)}$. The results were limited by high attrition, small sample sizes and non-adjustment for cluster design in the analysis. The eight non-RCT had potential biases associated with uncontrolled confounders ${ }^{(8-13)}$. Most relevant to the present study are two non-RCT iodine intervention trials that supplemented directly children from birth to 12 months and found effect sizes for mental development when tested at $2-5$ years ranging from $-0 \cdot 31$ to $0 \cdot 33^{(14,15)}$. Consequently, there is little evidence regarding the effects of iodine given to children in the first 2 years of life, and no published RCT that assessed effects of iodised salt on mental development at this age ${ }^{(16)}$.

The present study was designed to examine the effects of introducing iodised salt on young children's mental development in Ethiopia where iodine deficiency ranked highest among African countries ${ }^{(17)}$. In 2005 , only $4.2 \%$ of households tested were using iodised salt ${ }^{(18)}$, although one publication reported that $20 \%$ of the households were using adequately

Abbreviations: DQ, developmental quotient; RCT, randomised controlled trials; TEM, technical error measurement; UIC, urinary iodine concentration.

* Corresponding author: K. Bougma, email karim.bougma@mail.mcgill.ca, kbougma@gmail.com 
iodised salt $(\geq 15 \text { parts per million }(\mathrm{ppm}))^{(19)}$; there was a $39.9 \%$ prevalence of goitre and a median urinary iodine concentration (UIC) of $24.5 \mu \mathrm{g} / \mathrm{l}$ among children aged 6 to 12 years ${ }^{(18)}$, indicating moderate to severe iodine deficiency ${ }^{(20)}$. The Government of Ethiopia passed universal salt iodisation (USI) legislation in 2011. As it was expected that iodised salt would gradually enter all markets as national production increased, this situation presented a unique opportunity to randomly assign early market introduction and assess the effect of iodised salt on young children's mental development. The study hypothesis was that mental development scores would be higher in young children in intervention communities exposed to iodised salt earlier in comparison with young children from control communities who received it later.

\section{Methods}

The reporting of this cluster-randomised trial follows the Consolidated Standards of Reporting Trials extended guidelines ${ }^{(21)}$.

\section{Study design and participants}

The study was a cluster-randomised effectiveness trial with district as the cluster that was the unit of randomisation. Randomisation of district clusters allowed for the distribution of salt to markets rather than to households or individuals. Within districts, one village was randomly selected to minimise contamination across treatment groups. Baseline and endline assessments were conducted to compare outcomes before and after the introduction of iodised salt.

Ethics approval was received from the Ethiopian Public Health Institute, McGill University and the National Research Ethics Review Committee (Ethiopia). Support letters were also obtained from Regional, Zonal and District Bureaus of Health. All mothers provided written informed consent. The trial was registered at ClinicalTrials.gov, NCT013496.

This study was carried out between 25 October 2010 and 13 October 2013 in sixty rural villages in Amhara, a northern region of Ethiopia. The Amhara region is divided into ten zones, each sub-divided into districts (woredas) and then into villages (kebeles). Of the ten Amhara zones, four were excluded for reasons of language, urbanisation, presence of communitybased medical school training and use of alternative salt distribution. The remaining six contiguous zones served as the sampling frame.

A study census team visited households in selected villages to enumerate all infants who would be aged 5-11 months during baseline data collection. Enrolment and baseline data collection were performed simultaneously. Infants whose mothers were under 18 years of age were excluded.

\section{Randomisation, allocation and masking}

From the seventy-five eligible districts in the six zones, sixty were randomly selected using a simple randomisation method. Next, thirty districts were randomly allocated to the intervention arm and the remaining thirty to the control arm. In all sixty districts, one village was randomly selected for data collection.
Only the principal investigators and the person monitoring salt markets were aware of the group allocation. The research assistants were not told of the treatment allocation; they were present in the field only at baseline and endline when markets uniformly had non-iodised and iodised salt, respectively. Participants were also unaware of their condition; they continued to buy salt from their usual market, and when asked during the endline survey $88.1 \%$ of mothers said they had not heard about iodised salt and $96.8 \%$ said they never bought it, although $91.6 \%$ of household salt was iodised. The iodisation process did not change the texture of the salt and the price was the same.

\section{Procedures for intervention delivery and monitoring}

The intervention consisted of introducing iodised salt to markets of the intervention villages in July 2012, ahead of its widespread distribution. The salt was harvested by national producers who began to iodise in sizeable amounts after March 2012. Once production began, but before enough was available to cover the country's needs, we worked with the two wholesalers in the Amhara region to bring iodised salt to the district markets used by intervention villagers. In the thirty control villages, iodised salt became gradually available through regular market channels once production was sufficient and legislation was enforced in October 2012. In July 2012, 70.4\% of households in the intervention arm were using iodised salt; this increased to $82.8 \%$ in August and to $89.5 \%$ in September, whereas in October only $66 \cdot 3 \%$ of households in the control villages were using iodised salt. Children in the intervention group received approximately 4 to 6 months more exposure to iodised salt than controls; thus, at endline, children in the intervention group had approximately 8 to 10 months of exposure to iodised salt, whereas children in the control group had 4 to 6 months of exposure.

\section{Outcome measures}

All surveys were translated and back-translated. Measures were field-tested in one village that was not part of the sample.

Primary outcomes: mental development. The primary outcomes were the cognitive, expressive language, receptive language and fine motor scores on the Bayley Scales of Infant and Toddler Development ${ }^{(22)}$, which are most commonly used internationally to assess skills acquired in the first 3 years of life. Bayley Scales have been used in Ethiopia ${ }^{(23-25)}$ and elsewhere $^{(26,27)}$. The tests were modified, as is usual, by having an illustrator provide context-relevant pictures for some of the cognitive and language items; administration instructions were followed with the exception that precise timing of certain items with a stopwatch was not done ${ }^{(25)}$. Otherwise, almost all of the test objects were appropriate for this setting. Field testing demonstrated high concurrent validity with age $(r>0.80)$ of the four subtests, and the expected urban-rural difference, using children aged between 6 and 24 months. Age-standardised scores from the test manual were used to create comparable scores across the different subscales (theoretic range of 0-19) and a summed composite score out of 76 . 


\section{Psychosocial stimulation and maternal depressive symptoms.}

Two variables that might influence mental development and alter as a result of introducing iodised salt are psychosocial stimulation and mothers' depression ${ }^{(28,29)}$.

Psychosocial stimulation was measured with a modified version of the Home Observation for Measurement of the Environment (HOME) Inventory, a forty-five-item observation and interview measure of opportunities for stimulation of the child around the home $\mathrm{e}^{(29,30)}$. Modifications were made to individual items to make them suitable for this rural context ${ }^{(31)}$. Each item received a score for being not observed/not present $(=0)$ or observed/present $(=1)$ for a specific kind of stimulation (e.g. child has any play material; the mother responds verbally to child's talk or gesture). The HOME has been used in many different countries and is strongly associated with mental development ${ }^{(29)}$. It could also be affected by iodised salt if mothers themselves in response to higher levels of iodine became more responsive and energetic when interacting with their child as iodine has been associated with higher levels of productivity $^{(32)}$. Concurrent validity was good in relation to mental development and mother's education $(r 0.13$ to 0.33 and $r 0 \cdot 16$, respectively, controlling for age, $P=0 \cdot 0001$ ).

Maternal depressive symptoms were assessed with the Center for Epidemiological Studies Depression Scale, a twenty-item depressive symptoms (feelings of low self-esteem, sad mood, low energy and worry) frequency rating over the past week, recorded as a $0-3$ score $^{(33)}$. Convergent validity with the SelfReporting Questionnaire ${ }^{(34)}$ was good with a subsample ( $n$ 30; $r 0.61 ; P=0.005)$. It was considered important to assess maternal depression because of its potential link to child health and development, and because some depressive symptoms such as lack of energy may be reduced with increasing levels of iodine ${ }^{(35)}$.

Anthropometric and goitre assessment. Age was determined from the date of birth obtained from immunisation cards or parental report using the Ethiopian calendar. Weight and length (or height for $\geq 24$ months), respectively, were measured using a mother-child scale (Tanita WB-100; Tanita Corporation of America) with a precision of $100 \mathrm{~g}$ and a portable measuring board (Shorr Productions) with a precision of $0 \cdot 1 \mathrm{~cm}$. All measurements were recorded using standard procedures, and weight and length/height were taken in duplicate and a third time if the discrepancy was above the World Health Organization cut-off ${ }^{(36)}$. Weight and length/height were translated into standard scores using the WHO age and sex growth standards ${ }^{(37,38)}$. Goitre was assessed by thyroid palpation according to WHO guidelines ${ }^{(20)}$.

Urine and blood. Casual urine samples of about $20 \mathrm{ml}$ were collected in iodine-free paediatric urine collection bags at baseline and in urine cups at endline and transferred into iodine-free urine tubes and protected from evaporation. The samples were then stored at $-20^{\circ} \mathrm{C}$ in the field, transferred in dry ice to the Ethiopian Public Health Institute laboratory in Addis Ababa and stored at $-20^{\circ} \mathrm{C}$ until analysed for iodine concentration, using the digestion method of Sandell-Kolthoff reaction ${ }^{(39,40)}$. Our partner laboratory enrolled in the Centers for Disease Control and Prevention Ensuring the Quality of Urinary Iodine Procedures programme and started controls with round 29 before the study and participated successfully in its external validation on subsequent rounds.

$\mathrm{Hb}$ concentration for the assessment of anaemia was measured immediately in a drop using a DIFF-SAFE blood dispenser (Alpha Scientific Corporation) from a venous blood sample. The azidemethemoglobin method ${ }^{(41)}$ with a HemoCueTM $201+$ portable photometer (HemoCue, Inc.) was used.

Breast-feeding, diet and illness. Breast-feeding and feeding practices were documented as reported by the mother. Dietary diversity over the past $24 \mathrm{~h}$ was calculated from a FFQ, using seven food categories, namely grains, legumes, milk, egg, meatfish, vitamin A-rich foods and other fruit and vegetables ${ }^{(42)}$, without consideration of whether it was a typical day. The diet diversity score ranged from 0 to 7 . Mothers were asked to recall symptoms of infant illness over the $14 \mathrm{~d}$ before the interview using standard questions from the 2005 Ethiopia Demographic and Health Survey (EDHS) ${ }^{(19)}$. The number of illnesses reported over the past $14 \mathrm{~d}$ was derived for analysis.

Household sociodemographics and salt. Household data reported by the mother included parents' education and occupation, household size and assets, and water and sanitation facilities based on items from the EDHS ${ }^{(19)}$. Assets score was the sum of the following items where each was given 0 if not possessed and 1 if possessed: bed, chair, table, watch, radio/ television, phone, lamp, pump, transport and donkey. The water and sanitation score was the sum of the following items: latrine, waste disposal and source of drinking water. Each item was given a score of 1 if it was appropriate and 0 if not appropriate. Mothers also reported the presence of goitre in any family member. Salt samples were collected for iodine qualitative rapid testing (MBI Kits International) and all positive samples at baseline and a subsample at endline were quantitatively tested by titration ${ }^{(20)}$. Adequately iodised salt was defined as salt with iodine level $\geq 15$ ppm after titration.

\section{Training and data collection}

The baseline survey was carried out between October 2011 and April 2012, and the endline survey using the same measures on the same children was conducted between March and October 2013. The villages were completed in the same order at both time points. Graduate psychology students from the local university were trained by psychologists to administer the Bayley Scales to children in their homes. Inter-observer reliability was high at baseline and endline at the end of a 14-d training, with inter-tester correlations ranging from 0.68 to 0.97 and differences in scores between the two testings being non-significant.

At baseline and endline, standardisation sessions for anthropometric measurements were organised. The technical error measurement (TEM) and the coefficient of reliability $R$ were good: weight (baseline: TEM $=0.1 \mathrm{~kg}, \quad R \quad 99.7 \%$; endline: $\mathrm{TEM}=0.1 \mathrm{~kg}, R 99 \cdot 8 \%$ ) and length/height (baseline: TEM= $0.5 \mathrm{~cm}, R$ 99.1\%; endline: $\mathrm{TEM}=0.4 \mathrm{~cm}, R 99.5 \%)^{(43-45)}$.

The team spent 2 to $3 \mathrm{~d}$ in each village at each time point. With the list of children from the previously conducted census, the research assistants consulted with the health extension 
workers and local guides and moved from house to house to enroll and test the children on the Bayley Scales and interview the mothers. They referred the mother with her child to the village centre (generally, health post, school or church) for the anthropometric measurements, thyroid assessment and blood and urine sampling.

\section{Statistical analyses}

Sample size estimation was based on a Bayley subtest standardised score of mean $=10, \mathrm{SD} 1 \cdot 5$, where $\alpha=0 \cdot 05$, power $=$ 0.80 and effect size $d=0 \cdot 20$. This yielded a sample size of 393/group. Assuming a loss-to-follow-up of $10 \%$ and a cluster size of twenty-six children per village, a design effect of $2 \cdot 0$ was required to accommodate intra-cluster correlation of 0.04 , yielding a sample size of 850/group.

Our analytic approach was similar to other studies based on the cluster-randomised design ${ }^{(46)}$. The data were analysed with SAS 9.3 (SAS Institute, Inc.). Baseline differences between intervention and control groups were assessed using SAS's PROC MIXED ANOVA for continuous variables and PROC GLIMMIX for categorical variables, to accommodate clusters. The main intention-totreat analysis examined differences in raw Bayley scores between children in the intervention and control groups using ANCOVA adjusting for clusters and covariates, namely child age at endline, the corresponding baseline subtest score and variables with differences between groups at baseline. Standardised scores are presented only for comparison purposes. Effect sizes, Cohen's $d$, were calculated with the adjusted means and the pooled standard deviation. Missing data were not imputed. Interaction terms were tested for possible effect modifiers.

\section{Results}

The trial profile is found in Fig. 1. Attrition rates of $17 \%$ were similar in the intervention and control groups. The attrition analysis showed that infants who remained in the trial ( $n$ 1563), compared with those lost to follow-up ( $n$ 272), had a higher weight-for-age $z$ score $(P=0.045)$ and water and sanitation score $(P=0.028)$, and had more people in their household $(P=0 \cdot 011)$. Thus, there were differences between those who completed the full trial and those lost to follow-up. No cluster or child was excluded from the analysis. Differences in sample sizes for different analyses are due to missing data.

Infants in the intervention and control groups were similar in baseline characteristics in age, maternal education, depressive symptoms and household assets. Despite randomisation, however, there were some differences between groups (see Table 1). The time between baseline and endline assessment was on average 15.8 months and not different between groups.

The results for iodised salt and UIC reveal that intervention children received greater exposure to iodised salt than controls. At baseline, $<10 \%$ of households used iodised salt. By July 2012, 70\% of intervention households sampled had iodised salt, whereas a similar level was reached in control households in October 2012 (66\%). The proportion of households using iodised salt increased to $94.4 \%$ in the intervention group and to $89.3 \%$ in the control group at endline, and adequately iodised salt ( $\geq 15 \mathrm{ppm}$ ) was found in $54.2 \%$ of intervention households and $54.7 \%$ of control households. At baseline, participants in both groups were severely iodine deficient; 68.0 and $77.1 \%$ of infants had UIC below $50 \mu \mathrm{g} / \mathrm{l}$ in the intervention and control groups, respectively. The ANCOVA of endline scores (Table 2), covarying baseline UIC, showed that both groups improved median iodine status but the difference favoured the intervention children (228.0 v. 155.1 $\mu \mathrm{g} / \mathrm{l} ; P=0.001)$.

The primary outcome analyses found that children in the intervention group scored higher than controls on the cognitive, receptive language and fine motor subtests at endline (Table 3 ). The effect of the intervention on expressive language was in the same direction. The composite mental development score combining all four subscores was higher in the intervention group compared with the control group $(P=0 \cdot 010)$. Effect sizes were small.

Analyses of other outcomes demonstrated that the iodised salt intervention had no effect on psychosocial stimulation, but it did reduce the number of depressive symptoms reported by mothers, compared with controls $(P=0.003)$ (Table 3$)$. When water and sanitation, diet and illness were examined in interaction terms with the iodine intervention for the composite Bayley score, effect sizes for the intervention increased from $d=0.14$ to $d=0.23$ to 0.28 (Table 4). This indicated that there was a four-point developmental quotient (DQ) difference between intervention and control children under certain conditions, namely better water and sanitation, better diet or some illness.

\section{Discussion}

This community-based cluster-randomised trial showed that earlier introduction of iodised salt had an effect on children's mental development scores. Early introduction of iodised salt improved verbal (receptive language) and non-verbal (cognitive and fine motor) scores, as well as the composite mental development score, of the children in the intervention group over those in the control group. Given the randomised design and the consistency of effects, this study provides strong evidence that introducing iodised salt can positively affect young children's mental development.

In contrast to our results, supplementation of pregnant women in two RCT yielded moderate effect sizes ${ }^{(6,7)}$, whereas supplementation of infants yielded no consistent effect ${ }^{(14,15)}$. Our effect sizes were $d=0 \cdot 13$ for the composite and between $0 \cdot 11$ and $0 \cdot 14$ for three subtests. These differences suggest that supplementation during infancy is effective, but less so than during fetal development, consistent with theoretical arguments based on the timing of brain development and the role of iodine in brain development ${ }^{(2,3,47-49)}$.

Our effect sizes are small but positive and consistent. They are probably lower than the 'real effect size' because our comparison group had delayed availability of iodised salt rather than no availability. Yet they are far below the reported $0 \cdot 90$ effect size reported in a 1994 meta-analysis where the authors reached the conclusion that 13.5 DQ points are lost because of iodine deficiency ${ }^{(50)}$. Limitations to that meta-analysis include the large age range of participants, the wide variety of sometimes non-validated tests and the non-randomised design of the studies $^{(5)}$. We presented limited evidence that the intervention 


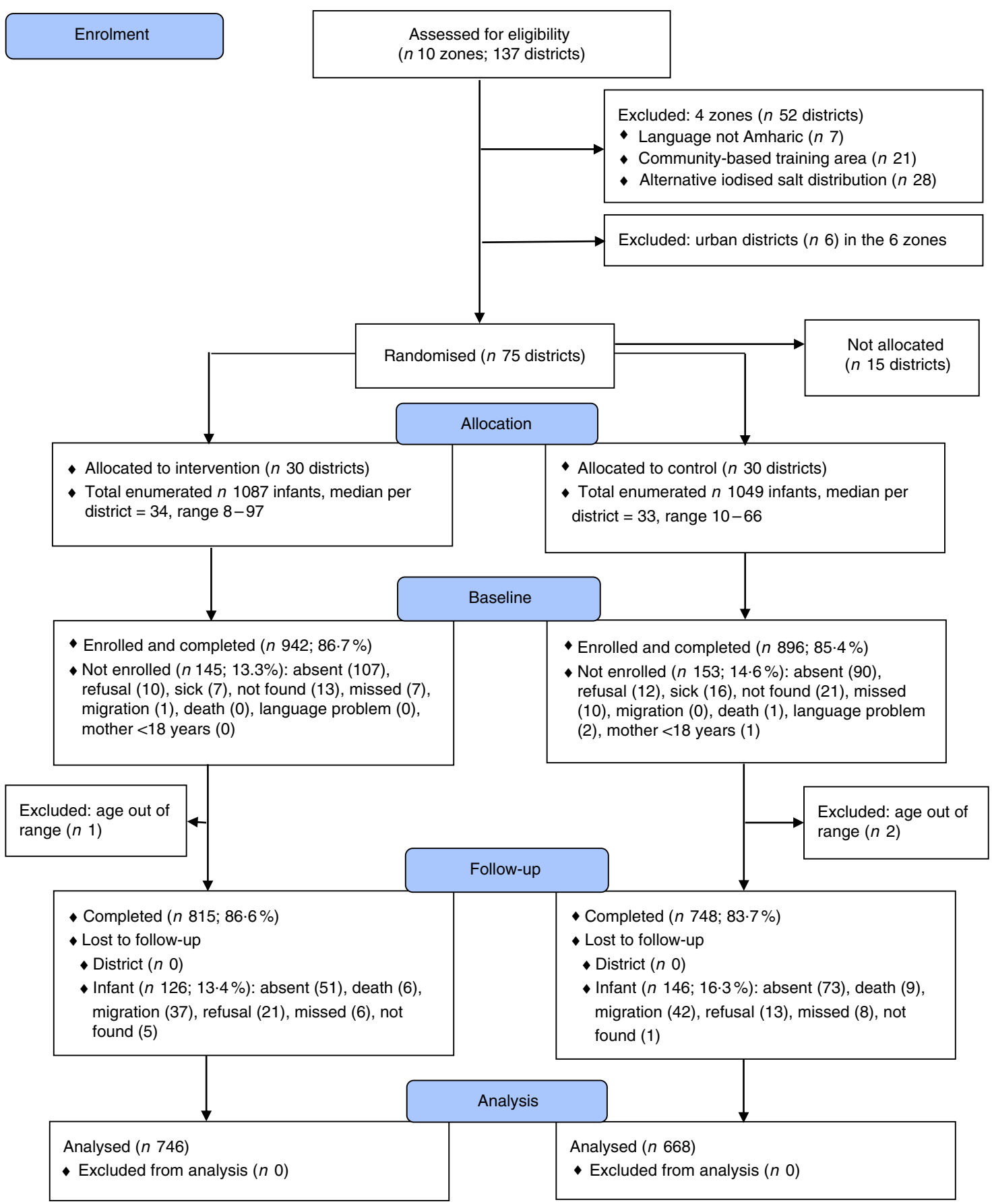

Fig. 1. Trial profile. Children 'missed' were children who were absent during the data collection period in their village. Children 'not found' were children who were neither identified nor recognised during the data collection. 'Migration' referred to children who were resettled in another village with their mother.

area received higher-quality iodised salt earlier than the control areas. However, given the expansive research area, market salt iodine levels were not frequently assessed and therefore we do not have as many salt iodine measures as we would have liked during the whole intervention period. On the basis of these limitations, it is more likely that DQ points lost owing to iodine deficiency could be between our current finding of 2.0 DQ points (effect size of $0 \cdot 13 \times$ SD of 15 ) and $7 \cdot 2$ DQ points from the two RCT where pregnant women were supplemented ${ }^{(6,7)}$.
Some recent and important reviews on nutrition and child development ${ }^{(51)}$ continue to cite the 1994 meta-analysis $^{(50)}$ as the reference for the cost of, or loss owing to, iodine deficiency. In our 2013 systematic review and meta-analysis on iodine and child development ${ }^{(5)}$, we reviewed the papers included in the 1994 meta-analysis and indicated the major limitations of that meta-analysis. The large effect size of 0.90 (13.5 DQ points) is an overestimate, based on our, as well as other, meta-analysis that has been published after 1994. It is time for nutrition and 
Table 1. Baseline characteristics of participating infants and families in the intervention and control groups in Amhara, Ethiopia (Mean values and standard deviations)

\begin{tabular}{|c|c|c|c|c|c|}
\hline & \multicolumn{2}{|c|}{ Intervention ( $n$ 941) } & \multicolumn{2}{|c|}{ Control (n 894) } & \multirow[b]{2}{*}{$P^{\star \star}$} \\
\hline & Mean & SD & Mean & SD & \\
\hline \multicolumn{6}{|l|}{ Infant } \\
\hline Sex (\% of girls) & \multicolumn{2}{|c|}{$48 \cdot 9$} & \multicolumn{2}{|c|}{$50 \cdot 3$} & 0.532 \\
\hline Age (months) & 8.51 & 1.40 & 8.48 & $1 \cdot 38$ & 0.614 \\
\hline Weight-for-age (z score) & -1.29 & $1 \cdot 23$ & -1.40 & $1 \cdot 21$ & 0.050 \\
\hline Weight-for-length (z score) & -0.47 & $1 \cdot 10$ & -0.53 & 1.09 & 0.273 \\
\hline Length-for-age ( $z$ score) & -1.56 & 1.29 & -1.67 & $1 \cdot 26$ & 0.070 \\
\hline Goitre (\%) & \multicolumn{2}{|c|}{0.8} & \multicolumn{2}{|c|}{0.6} & 0.909 \\
\hline Dietary diversity $(0-7)^{\star}$ & 0.93 & 0.99 & 0.83 & 0.94 & 0.030 \\
\hline Illnesses in the past $14 \mathrm{~d}(0-6)$ & 0.93 & 1.09 & 0.94 & 1.09 & 0.929 \\
\hline $\mathrm{Hb}(\mathrm{g} / \mathrm{l})$ & $109 \cdot 4$ & $18 \cdot 27$ & $112 \cdot 3$ & $18 \cdot 71$ & 0.002 \\
\hline Bayley cognitive (raw)† & 30.46 & 4.42 & $30 \cdot 63$ & $4 \cdot 31$ & 0.411 \\
\hline Bayley expressive language (raw)† & 9.65 & 3.04 & 9.98 & 2.97 & 0.020 \\
\hline Bayley receptive language (raw) $\dagger$ & $10 \cdot 25$ & $2 \cdot 42$ & $10 \cdot 51$ & $2 \cdot 36$ & 0.022 \\
\hline Bayley fine motor (raw)† & $20 \cdot 77$ & $3 \cdot 32$ & $21 \cdot 10$ & 3.45 & 0.043 \\
\hline HOME stimulation $(0-45) \ddagger$ & 19.97 & $4 \cdot 70$ & $20 \cdot 58$ & 4.58 & 0.006 \\
\hline \multicolumn{6}{|l|}{ Mother } \\
\hline Age (years) & $28 \cdot 4$ & $6 \cdot 7$ & $27 \cdot 8$ & $6 \cdot 4$ & 0.039 \\
\hline Level of education, $\geq 1$ year (\%) & \multicolumn{2}{|c|}{$18 \cdot 2$} & \multicolumn{2}{|c|}{$18 \cdot 0$} & 0.975 \\
\hline Occupation: farming and homemaking (\%) & \multicolumn{2}{|c|}{$97 \cdot 1$} & \multicolumn{2}{|c|}{$96 \cdot 5$} & 0.526 \\
\hline Maternal depressive symptoms $(0-60) \S$ & $16 \cdot 49$ & $9 \cdot 65$ & $16 \cdot 15$ & $9 \cdot 34$ & 0.449 \\
\hline \multicolumn{6}{|l|}{ Father } \\
\hline Age (years) & $35 \cdot 7$ & $8 \cdot 1$ & $36 \cdot 4$ & $8 \cdot 8$ & 0.089 \\
\hline Level of education, $\geq 1$ year (\%) & \multicolumn{2}{|c|}{$20 \cdot 8$} & \multicolumn{2}{|c|}{$19 \cdot 8$} & 0.926 \\
\hline Occupation, farming (\%) & \multicolumn{2}{|c|}{$97 \cdot 6$} & \multicolumn{2}{|c|}{$98 \cdot 3$} & 0.389 \\
\hline \multicolumn{6}{|l|}{ Household } \\
\hline Household size, number of people & $5 \cdot 9$ & $2 \cdot 7$ & $5 \cdot 8$ & 2.4 & 0.483 \\
\hline Assets $(0-10) \|$ & 4.67 & 0.95 & 4.68 & 0.93 & 0.914 \\
\hline Water and sanitation (0-3) & 1.48 & 0.88 & 1.65 & 0.90 & $<0.001$ \\
\hline Family goitre (\%) & \multicolumn{2}{|c|}{$31 \cdot 4$} & \multicolumn{2}{|c|}{$47 \cdot 6$} & $<0.001$ \\
\hline
\end{tabular}

HOME, Home Observation for Measurement of the Environment.

* Diet diversity score = sum (grains, legumes, milk, egg, meat-fish, vitamin A-rich foods and fruit and vegetables).

$\dagger$ Maximum scores on the Bayley Scales are as follows: cognitive (91), expressive language (48), receptive language (49) and fine motor (66)

$\ddagger$ Assessed with the HOME Inventory.

$\S$ Assessed with the Center for Epidemiological Studies Depression Scale.

\|l Assets score = sum (bed, chair, table, watch, radio-television, phone, lamp, pump, transport and donkey).

I Water and sanitation score = sum (latrine, waste disposal and source of drinking water).

** $P$ values based on ANOVA adjusting for clusters.

Table 2. Comparison of household iodised salt and children's iodine status in the intervention and control groups at baseline and endline in Amhara, Ethiopia

(Percentages and interquartile ranges (IQR))

\begin{tabular}{|c|c|c|c|c|c|c|c|c|c|c|}
\hline & \multicolumn{5}{|c|}{ Baseline } & \multicolumn{5}{|c|}{ Endline } \\
\hline & \multicolumn{2}{|c|}{$\begin{array}{l}\text { Intervention } \\
\quad(n \text { 840) }\end{array}$} & \multicolumn{2}{|c|}{$\begin{array}{l}\text { Control } \\
(n 812)\end{array}$} & \multirow[b]{2}{*}{$P$} & \multicolumn{2}{|c|}{$\begin{array}{l}\text { Intervention } \\
\quad(n 743)\end{array}$} & \multicolumn{2}{|c|}{$\begin{array}{l}\text { Control } \\
(n 654)\end{array}$} & \multirow[b]{2}{*}{$P$} \\
\hline & $\%$ & IQR & $\%$ & IQR & & $\%$ & IQR & $\%$ & IQR & \\
\hline lodised salt (\% of households) & 6.6 & & 5.4 & & 0.379 & 94.4 & & $89 \cdot 3$ & & 0.024 \\
\hline $\begin{array}{l}\text { Adequately iodised salt, } \geq 15 \mathrm{ppm} \text { ( } \% \text { of households, } \\
\text { among households with iodised salt) }\end{array}$ & $69 \cdot 6$ & & $76 \cdot 2$ & & 0.394 & $54 \cdot 2$ & & 54.7 & & 0.994 \\
\hline UIC, median and IQR $(\mu \mathrm{g} / \mathrm{I}) \dagger$ & 21.4 & $2 \cdot 0-70 \cdot 1$ & 14.8 & $0.5-42.9$ & 0.001 & 228.0 & $123.4-411.5$ & $155 \cdot 0$ & $81 \cdot 4-283.9$ & 0.001 \\
\hline lodine deficiency, UIC $<100 \mu \mathrm{g} / \mathrm{l}(\%) \dagger$ & 83.8 & & 91.0 & & 0.131 & 28.3 & & 39.0 & & 0.016 \\
\hline lodine deficiency, UIC $<50 \mu \mathrm{g} / \mathrm{l}(\%) \dagger$ & 68.0 & & $77 \cdot 1$ & & 0.450 & $6 \cdot 8$ & & 13.9 & & 0.009 \\
\hline lodine deficiency, UIC $<20 \mu \mathrm{g} / \mathrm{l}(\%) \dagger$ & $48 \cdot 8$ & & $56 \cdot 2$ & & 0.559 & $1 \cdot 2$ & & $5 \cdot 0$ & & 0.021 \\
\hline
\end{tabular}

ppm, parts per million; UIC, urinary iodine concentration.

* Based on titration.

† Samples were obtained at baseline on intervention, $n$ 730; control, $n 715$; at endline on intervention, $n 667$; control, $n 612$ children.

development researchers to use the up-to-date reviews and meta-analyses and stop citing the 1994 overestimated effect size. Finally, given that iodine has a more consistent effect on mental development in early life, researchers should focus on the period between preconception and early childhood rather than school-age children. 
Table 3. Effects of iodised salt intervention on infants' iodine status and development, and maternal depressive symptoms, in Amhara, Ethiopia (Mean values and standard deviations; Cohen's $d$ and $95 \%$ confidence intervals)

\begin{tabular}{|c|c|c|c|c|c|c|c|c|c|}
\hline \multirow[b]{2}{*}{ Outcomes } & \multicolumn{2}{|c|}{ Intervention ( $n$ 746) } & \multicolumn{2}{|c|}{ Control ( $n$ 668) } & \multicolumn{2}{|c|}{$F$ test $^{*}$} & \multicolumn{2}{|c|}{ Effect size } & \multirow{2}{*}{$\begin{array}{c}\text { Intra-cluster } \\
\text { correlation } \\
\text { coefficient }\end{array}$} \\
\hline & Mean & SD & Mean & SD & $F$ & $P$ & $d$ & $95 \% \mathrm{Cl}$ & \\
\hline \multicolumn{10}{|l|}{ Bayley Scales, version III } \\
\hline Cognitive score (raw) $\dagger$ & $53 \cdot 27$ & 5.96 & 52.54 & 5.70 & 5.31 & 0.021 & 0.13 & $0.03,0.23$ & 0.060 \\
\hline Cognitive score (standardised; 0-19)‡ & $6 \cdot 16$ & 2.33 & 5.88 & 2.24 & & & & & \\
\hline Receptive language score (raw) $\dagger$ & $20 \cdot 71$ & 4.12 & $20 \cdot 18$ & 3.96 & 7.97 & 0.005 & 0.13 & $0.03,0.24$ & 0.078 \\
\hline Receptive language score (standardised; 0-19)‡ & $7 \cdot 01$ & 2.25 & 6.75 & $2 \cdot 16$ & & & & & \\
\hline Expressive language score (raw) $\dagger$ & 21.47 & $4 \cdot 80$ & $21 \cdot 06$ & $4 \cdot 40$ & $2 \cdot 95$ & 0.086 & 0.09 & $-0.02,0.19$ & 0.038 \\
\hline Expressive language score (standardised; 0-19)‡ & $6 \cdot 25$ & $2 \cdot 17$ & 6.05 & 1.99 & & & & & \\
\hline Fine motor score (raw)† & 35.45 & 3.57 & 34.94 & 3.33 & 8.94 & 0.003 & $0 \cdot 15$ & $0.04,0.25$ & 0.074 \\
\hline Fine motor score (standardised; 0-19)‡ & $7 \cdot 73$ & $2 \cdot 76$ & 7.36 & 2.57 & & & & & \\
\hline Composite score (raw) $\dagger$ & $130 \cdot 70$ & $16 \cdot 89$ & $128 \cdot 50$ & $15 \cdot 43$ & 6.49 & 0.011 & 0.14 & $0.03,0.24$ & 0.061 \\
\hline Composite score (standardised; 0-76)‡ & $27 \cdot 78$ & 8.73 & $26 \cdot 88$ & 8.22 & & & & & \\
\hline HOME stimulation $(0-45) \S$ & $24 \cdot 22$ & 5.47 & 23.88 & 5.46 & 1.30 & 0.255 & 0.06 & $-0.04,0.17$ & 0.053 \\
\hline Maternal depressive symptoms $(0-60) \|$ & $16 \cdot 12$ & 9.50 & $17 \cdot 74$ & 10.47 & 8.84 & 0.003 & $0 \cdot 16$ & $0.06,0.27$ & 0.061 \\
\hline
\end{tabular}

HOME, Home Observation for Measurement of the Environment.

* ANCOVA adjusted for cluster, baseline covariates (water and sanitation score, HOME score, weight-for-age $z$ score) along with corresponding baseline Bayley score of the outcome and age at endline.

$\dagger$ Maximum raw scores on the Bayley Scales are as follows: cognitive (91), expressive language (48), receptive language (49) and fine motor (66).

$\ddagger$ Standardised scores are shown for comparison purpose with other studies.

$\S$ Assessed with the HOME Inventory.

I| Assessed with the Center for Epidemiological Studies Depression Scale.

Table 4. Significant interactions between iodised salt intervention and modifier variables on infants' mental development outcomes (Mean values and standard deviations; Cohen's $d$ and $95 \%$ confidence intervals)

\begin{tabular}{|c|c|c|c|c|c|c|c|c|c|c|c|c|c|c|c|}
\hline \multirow[b]{2}{*}{ Outcomes } & \multicolumn{3}{|l|}{ Modifier* } & \multicolumn{2}{|c|}{ Intervention } & \multicolumn{2}{|c|}{ Control } & \multicolumn{2}{|c|}{ Intervention† } & \multicolumn{2}{|c|}{ Modifier† } & \multicolumn{2}{|c|}{ Interaction† } & \multicolumn{2}{|c|}{ Effect size } \\
\hline & Modifier & Level & $n$ & Mean & SD & Mean & SD & $F$ & $P$ & $F$ & $P$ & $F$ & $P$ & $d$ & $95 \% \mathrm{Cl}$ \\
\hline \multirow[t]{6}{*}{ Cognitive } & \multirow[t]{2}{*}{ Water and sanitation $\ddagger$} & 0 to 1 & 659 & 52.45 & 6.02 & 52.45 & 5.51 & \multirow{2}{*}{$6 \cdot 13$} & \multirow[t]{2}{*}{0.013} & \multirow[t]{2}{*}{$5 \cdot 91$} & \multirow[t]{2}{*}{0.015} & \multirow[t]{2}{*}{$3 \cdot 83$} & \multirow[t]{2}{*}{0.051} & -0.00 & $-0.16,0.15$ \\
\hline & & 2 to 3 & 755 & $54 \cdot 12$ & 5.79 & $52 \cdot 60$ & $5 \cdot 84$ & & & & & & & 0.26 & $0.11,0.41$ \\
\hline & \multirow[t]{2}{*}{ Dietary diversity§ } & 0 to 1 & 1032 & $52 \cdot 72$ & 5.97 & $52 \cdot 31$ & $5 \cdot 72$ & \multirow{2}{*}{7.35} & \multirow[t]{2}{*}{0.007} & \multirow[t]{2}{*}{$5 \cdot 71$} & \multirow[t]{2}{*}{0.017} & \multirow[t]{2}{*}{9.73} & \multirow[t]{2}{*}{0.002} & 0.07 & $-0.05,0.19$ \\
\hline & & 2 to 7 & 382 & 54.60 & $5 \cdot 76$ & $53 \cdot 23$ & $5 \cdot 60$ & & & & & & & 0.24 & $0.04,0.44$ \\
\hline & \multirow[t]{2}{*}{ Illness } & None & 673 & $52 \cdot 91$ & 5.73 & $53 \cdot 12$ & 5.77 & \multirow{2}{*}{5.06} & \multirow[t]{2}{*}{0.025} & \multirow[t]{2}{*}{0.66} & \multirow[t]{2}{*}{0.415} & \multirow[t]{2}{*}{8.96} & \multirow[t]{2}{*}{0.003} & -0.04 & $-0.19,0.11$ \\
\hline & & Some & 738 & 53.56 & $6 \cdot 15$ & 51.98 & 5.58 & & & & & & & 0.27 & $0.12,0.41$ \\
\hline Receptive language & Dietary diversity & 0 to 1 & 1030 & $20 \cdot 26$ & 3.88 & $20 \cdot 05$ & 3.93 & 8.99 & 0.003 & 12.87 & $<0.001$ & $4 \cdot 18$ & 0.041 & 0.05 & $-0.07,0.18$ \\
\hline & & 2 to 7 & 381 & $21 \cdot 79$ & 4.47 & 20.58 & 4.03 & & & & & & & 0.28 & $0.08,0.49$ \\
\hline Expressive language & Water and sanitation & 0 to 1 & 659 & $20 \cdot 77$ & 4.52 & $20 \cdot 88$ & 4.22 & 3.37 & 0.067 & 9.06 & 0.003 & $4 \cdot 16$ & 0.042 & -0.02 & $-0.18,0.13$ \\
\hline & & 2 to 3 & 753 & $22 \cdot 19$ & 4.97 & $21 \cdot 20$ & 4.50 & & & & & & & 0.21 & $0.07,0.35$ \\
\hline & Dietary diversity & 0 to 1 & 1031 & 20.95 & 4.58 & $20 \cdot 92$ & 4.35 & 5.93 & 0.015 & 11.49 & 0.001 & $5 \cdot 39$ & 0.020 & 0.01 & $-0.11,0.13$ \\
\hline & & 2 to 7 & 381 & $22 \cdot 70$ & 5.08 & 21.50 & 4.52 & & & & & & & 0.25 & $0.04,0.45$ \\
\hline Fine motor & Water and sanitation & 0 to 1 & 658 & 34.95 & 3.29 & 34.91 & $3 \cdot 30$ & 8.83 & 0.003 & 6.58 & 0.010 & $6 \cdot 07$ & 0.014 & 0.01 & $-0.14,0.17$ \\
\hline & & 2 to 3 & 750 & 35.97 & 3.77 & 34.96 & 3.37 & & & & & & & 0.28 & $0.14,0.43$ \\
\hline Bayley composite & Water and sanitation & 0 to 1 & 659 & $128 \cdot 3$ & $16 \cdot 2$ & $128 \cdot 1$ & $14 \cdot 7$ & $7 \cdot 16$ & 0.008 & $6 \cdot 27$ & 0.012 & 3.60 & 0.058 & 0.01 & $-0.14,0.17$ \\
\hline & & 2 to 3 & 755 & $133 \cdot 1$ & $17 \cdot 2$ & $128 \cdot 9$ & $15 \cdot 9$ & & & & & & & 0.25 & $0.11,0.40$ \\
\hline & Dietary diversity & 0 to 1 & 1032 & 128.9 & $16 \cdot 0$ & $128 \cdot 0$ & $15 \cdot 2$ & $9 \cdot 78$ & 0.002 & $10 \cdot 13$ & 0.002 & $4 \cdot 35$ & 0.037 & 0.06 & $-0.06,0.18$ \\
\hline & & 2 to 7 & 382 & 134.9 & $18 \cdot 2$ & $130 \cdot 1$ & $16 \cdot 0$ & & & & & & & 0.28 & $0.07,0.48$ \\
\hline & Illness & None & 673 & 129.8 & $15 \cdot 8$ & 129.6 & $15 \cdot 4$ & 6.05 & 0.014 & 0.12 & 0.351 & 4.41 & 0.036 & 0.01 & $-0.14,0.16$ \\
\hline & & Some & 738 & $131 \cdot 3$ & $17 \cdot 7$ & $127 \cdot 5$ & $15 \cdot 4$ & & & & & & & 0.23 & $0.08,0.37$ \\
\hline
\end{tabular}

* Modifiers' level/cut-off were set close to median to balance cell sizes as much as possible. Only dietary diversity had a conventional cut-off (set at 4 or more), but this would have left cell sizes too discrepant.

$\dagger$ All analyses were conducted using covariates current age and the baseline scores of the corresponding variable.

‡ Water and sanitation score $=$ sum (latrine, waste disposal and source of drinking water).

$\S$ Diet diversity score = sum (grains, legumes, milk, egg, meat-fish, vitamin A-rich-foods and fruit and vegetables).

Other researchers have suggested that iodine deficiency is associated with depression $^{(35,52)}$. Although symptoms of depression and hypothyroidism overlap (e.g. fatigue, lack of energy for activities, trouble making decisions), it is not clear whether biochemical mechanisms involving 5-hydroxytryptamine connect the two ${ }^{(52)}$.

Maternal depressive symptoms were reduced in the intervention group compared with the control group. The effect size of 0.16 is small but noteworthy and not studied or reported in other iodine supplementation studies.

The 2015 national micronutrient survey reported that only $15 \%$ of salt was adequately iodised $(\geq 15 \mathrm{ppm})^{(53)}$, whereas we had at endline in 2013 about $50 \%$ adequately iodised salt. Therefore, the 2015 survey showed that the quality of the iodised salt is still a problem. 
The study has several limitations. Both groups had iodised salt by the endline, and thus the distinction between them was minimised at this point. A randomised design such as ours could be ethical only if we did not withhold iodised salt when it became widely available, from control sites. Thus, the difference between the two treatment groups was in duration of exposure. Monitoring of the intervention indicated that the intervention group received longer exposure to iodised salt (8 to 10 months $v .4$ to 6 months) and higher-quality iodised salt earlier than control sites. The Amhara Regional Bureau of Health implemented in May-June 2012 its iodine capsule campaign for children aged 6 to 23 months and pregnant and lactating women after the baseline in our study area. Poppy seed oil iodised capsules have been reported to protect for 10 months ${ }^{(54)}$. Capsules were given to children in both intervention and control groups 9-14 months before endline. It may have affected the UIC and the mental development, but we assume that both groups were affected equally. The median UIC for both groups might have been slightly higher owing to the supplements $(228 \mu \mathrm{g} / \mathrm{l}$ (intervention) $v .155 \cdot 0 \mu \mathrm{g} / \mathrm{l}$ (control)); the difference is most likely due to iodised salt intake. This is based on additional data from older preschool-aged children who did not receive the iodised oil supplements and whose endline UIC medians were similarly different: $165.8 \mu \mathrm{g} / \mathrm{l}$ (intervention) and $121 \cdot 1 \mu \mathrm{g} / \mathrm{l}$ (control) ${ }^{(55)}$. However, our ability to detect differences may have been reduced by the capsule's effect. The children's iodine intake through the family meal and breast milk ${ }^{(56)}$ was not measured, but UIC indicated that it was sufficient at endline, particularly for intervention children.

The strengths of our study were the randomised design, the large sample size and low attrition, and the measurement of, and adjustment for, covariates. This was an intention-to-treat analysis and was adjusted for the cluster design. The mental development test used, the Bayley Scales, is robust and addresses four domains of mental development. Our data provide strong evidence for the importance of the introduction of iodised salt to improve mental development of children. These findings are relevant for policymakers and governments and are generalisable to countries in similar situations to Ethiopia.

\section{Acknowledgements}

The authors thank Husein Mohammed, Valerie Friesen, Daisy R Singla, Aregash Samuel, Cherinet Abuye, Dawd Gashu, Biruk A Abegaz, Yayesew C Getnet, Fasil E Mengestie, Agernesh Alem, Abeyot B Malede, Dilnesaw A Zerfu, Adamu T Belay, Meseret W Mengistie, the research assistants, the national office of Nutrition International (NI) in Ethiopia, the Amhara Regional Bureau of Health and the health extension workers. The authors are grateful to all the mothers and children who participated in the study.

NI, an international not-for-profit organisation, conceived the idea for this study and commissioned and funded McGill University to design and implement it. NI did a site visit during the baseline data collection, provided technical assistance in understanding and modifying salt markets, and reviewed this manuscript before publication. As part of separate, ongoing efforts, NI provided technical and financial support for the USI programme. McGill University was fully responsible for the design, conduct, analysis and writing of the study with no interference from NI.

K. B., F. E. A. and G. S. M. designed the study and prepared the measures; K. B., F. E. A., T. M. L. and G. S. M. trained the research assistants; K. B., F. E. A., E. A. F. and G. S. M. conducted the data management and/or analysis; K. B. implemented the fieldwork and wrote the first draft of the manuscript. All authors edited the report and approved the final manuscript.

The authors declare that there are no conflicts of interest.

\section{References}

1. Black MM, Walker SP, Fernald LC, et al. (2017) Early childhood development coming of age: science through the life course. Lancet 389, 77-90.

2. Berbel P, Auso E, Garcia-Velasco JV, et al. (2001) Role of thyroid hormones in the maturation and organisation of rat barrel cortex. Neuroscience 107, 383-394.

3. Zoeller RT \& Rovet J (2004) Timing of thyroid hormone action in the developing brain: clinical observations and experimental findings. J Neuroendocrinol 16, 809-818.

4. Delange F (1994) The disorders induced by iodine deficiency. Thyroid 4, 107-128.

5. Bougma K, Aboud F, Harding K, et al. (2013) Iodine and mental development of children 5 years old and under: a systematic review and meta-analysis. Nutrients 5, 1384-1416.

6. Pretell EA, Torres T, Zenteno V, et al. (1972) Prophylaxis of endemic goiter with iodized oil in rural Peru. Adv Exp Med Biol 30, 249-265.

7. Thilly CH (1981) Psychomotor development in regions with endemic goiter. In Fetal Brain Disorders: Recent Approaches to the Problem of Mental Deficiency, pp. 265-282 [BS Hetzel and RM Smith, editors]. Amsterdam; New York; New York, NY: Elsevier/North-Holland Biomedical Press; Sole distributors for the USA and Canada, Elsevier North-Holland.

8. Connolly KJ, Pharoah PO \& Hetzel BS (1979) Fetal iodine deficiency and motor performance during childhood. Lancet ii, $1149-1151$.

9. Untoro J (1999) Use of oral iodized oil to control iodine deficiency in Indonesia. PhD Thesis, Wageningen Agricultural University.

10. van den Briel $\mathrm{T}$, West $\mathrm{CE}$, Bleichrodt $\mathrm{N}$, et al. (2000) Improved iodine status is associated with improved mental performance of schoolchildren in Benin. Am J Clin Nutr $\mathbf{7 2}$, $1179-1185$.

11. Huda SN, Grantham-McGregor SM \& Tomkins A (2001) Cognitive and motor functions of iodine-deficient but euthyroid children in Bangladesh do not benefit from iodized poppy seed oil (Lipiodol). J Nutr 131, 72-77.

12. Zimmermann MB, Connolly K, Bozo M, et al. (2006) Iodine supplementation improves cognition in iodine-deficient schoolchildren in Albania: a randomized, controlled, doubleblind study. Am J Clin Nutr 83, 108-114.

13. Gordon RC, Rose MC, Skeaff SA, et al. (2009) Iodine supplementation improves cognition in mildly iodinedeficient children. Am J Clin Nutr 90, 1264-1271.

14. Cao XY, Jiang XM, Dou ZH, et al. (1994) Timing of vulnerability of the brain to iodine deficiency in endemic cretinism. N Engl J Med 331, 1739-1744.

15. Trowbridge FL (1972) Intellectual assessment in primitive societies, with a preliminary report of a study of the effects of early iodine supplementation on intelligence. Adv Exp Med Biol 30, 137-149.

16. Melse-Boonstra A \& Jaiswal N (2010) Iodine deficiency in pregnancy, infancy and childhood and its consequences for 
brain development. Best Pract Res Clin Endocrinol Metab 24, 29-38.

17. Andersson M, Karumbunathan V \& Zimmermann MB (2012) Global iodine status in 2011 and trends over the past decade. J Nutr 142, 744-750.

18. Abuye C, Berhane Y, Akalu G, et al. (2007) Prevalence of goiter in children 6 to 12 years of age in Ethiopia. Food Nutr Bull 28, 391-398.

19. Central Statistical Agency (Ethiopia), ORC Macro (2006) Ethiopia Demographic and Health Survey 2005. Addis Ababa and Calverton, MD: Central Statistical Agency and ORC Macro.

20. World Health Organization (2007) Assessment of Iodine Deficiency Disorders and Monitoring their Elimination. A Guide for Program Managers. Geneva: WHO/UNICEF/ICCIDD.

21. Campbell MK, Piaggio G, Elbourne DR, et al. (2012) Consort 2010 statement: extension to cluster randomised trials. BMJ 345, e 5661.

22. Bayley N (2006) Bayley Scales of Infant and Toddler Development. San Antonio, TX: Psychological Corporation.

23. Aboud FE \& Alemu T (1995) Nutrition, maternal responsiveness and mental development of Ethiopian children. Soc Sci Med 41, 725-732.

24. Drewett R, Wolke D, Asefa M, et al. (2001) Malnutrition and mental development: is there a sensitive period? A nested case-control study. J Child Psychol Psychiatry 42, 181-187.

25. Servili C, Medhin G, Hanlon C, et al. (2010) Maternal common mental disorders and infant development in Ethiopia: the P-MaMiE Birth Cohort. BMC Public Health 10, 693.

26. Aboud FE, Singla DR, Nahil MI, et al. (2013) Effectiveness of a parenting program in Bangladesh to address early childhood health, growth and development. Soc Sci Med 97, 250-258.

27. Yousafzai AK, Rasheed MA, Rizvi A, et al. (2014) Effect of integrated responsive stimulation and nutrition interventions in the Lady Health Worker programme in Pakistan on child development, growth, and health outcomes: a clusterrandomised factorial effectiveness trial. Lancet 384, 1282-1293.

28. Milgrom J \& Holt C (2014) Early intervention to protect the mother-infant relationship following postnatal depression: study protocol for a randomised controlled trial. Trials 15, 385.

29. Aboud FE \& Yousafzai AK (2015) Global health and development in early childhood. Annu Rev Psychol 66, 433-457.

30. Bradley RH \& Corwyn RF (2005) Caring for children around the world: a view from HOME. Int J Behav Dev 29, 468-478.

31. Aboud FE (2007) Evaluation of an early childhood parenting programme in rural Bangladesh.J Health Popul Nutr 25, 3-13.

32. Hetzel BS (1988) The Prevention and Control of Iodine Deficiency Disorders. Discussion by F Delange, JB Stanbury and FE Viteri. Nutrition Policy Discussion Paper no. 3. Geneva: United Nations.

33. Radloff LS (1977) The CES-D Scale: a self-report depression scale for research in the general population. Appl Psychol Meas 1, 385-401.

34. Beusenberg M \& Orley J (1994) A User's Guide to Self Reporting Questionnaire (SRQ). Geneva: Division of Mental Health, WHO.

35. Haggerty JJ Jr \& Prange AJ Jr (1995) Borderline hypothyroidism and depression. Annu Rev Med 46, 37-46.

36. World Health Organization Multicentre Growth Reference Study Group, de Onis M (2006) Reliability of anthropometric measurements in the WHO Multicentre Growth Reference Study. Acta Paediatr Suppl 450, 38-46.

37. World Health Organization Multicentre Growth Reference Study Group (2006) WHO Child Growth Standards: Length/Height-for-Age, Weight-for-age, Weight-for-Length,
Weight-for-Height and Body Mass Index-for-Age: Methods and Development. Geneva: WHO.

38. World Health Organization Multicentre Growth Reference Study Group (2007) WHO Child Growth Standards: Head Circumference-for-Age, Arm Circumference-for-Age, Triceps Skinfold-for-Age and Subscapular Skinfold-for-Age: Methods and Development. Geneva: WHO.

39. Sandell EB \& Kolthoff IM (1937) Micro determination of iodine by a catalytic method. Microchimica Acta 1, 9-25.

40. Pino S, Fang SL \& Braverman LE (1996) Ammonium persulfate: a safe alternative oxidizing reagent for measuring urinary iodine. Clin Chem 42, 239-243.

41. Vanzetti G (1966) An azide-methemoglobin method for hemoglobin determination in blood. J Lab Clin Med 67, 116-126.

42. Daelmans B, Dewey K \& Arimond M (2009) New and updated indicators for assessing infant and young child feeding. Food Nutr Bull 30, S256-S262.

43. Ulijaszek SJ \& Kerr DA (1999) Anthropometric measurement error and the assessment of nutritional status. Br J Nutr 82, 165-177.

44. World Health Organization (2006) Reliability of anthropometric measurements in the WHO Multicentre Growth Reference Study. Acta Paediatr Suppl 450, 38-46.

45. Ayele B, Aemere A, Gebre T, et al. (2012) Reliability of measurements performed by community-drawn anthropometrists from rural Ethiopia. PLOS ONE 7, e30345.

46. Kramer MS, Aboud F, Mironova E, et al. (2008) Breastfeeding and child cognitive development: new evidence from a large randomized trial. Arch Gen Psychiatry 65, 578-584.

47. Berbel P, Guadano-Ferraz A, Martinez M, et al. (1993) Organization of auditory callosal connections in hypothyroid adult rats. Eur J Neurosci 5, 1465-1478.

48. Berbel P, Guadano-Ferraz A, Angulo A, et al. (1994) Role of thyroid hormones in the maturation of interhemispheric connections in rats. Behav Brain Res 64, 9-14.

49. Bernal J (2005) Thyroid hormones and brain development. Vitam Horm 71, 95-122.

50. Bleichrodt N \& Born PM (1994) A meta-analysis of research on iodine and its relationship to cognitive development. In The Damaged Brain of Iodine Deficiency: Cognitive, Behavioral, Neuromotor and Educative Aspects, pp. 195-200 [JB Stanbury, editor]. New York: Cognizant Communication Corporation.

51. Black RE, Victora CG, Walker SP, et al. (2013) Maternal and child undernutrition and overweight in low-income and middle-income countries. Lancet 382, 427-451.

52. Cleare AJ, McGregor A \& O'Keane V (1995) Neuroendocrine evidence for an association between hypothyroidism, reduced central 5-HT activity and depression. Clin Endocrinol (Oxf) 43, 713-719.

53. Ethiopian Public Health Institute (2016) Ethiopian National Micronutrient Survey. Addis Ababa: Ethiopian Public Health Institute.

54. Untoro J, Schultink W, West CE, et al. (2006) Efficacy of oral iodized peanut oil is greater than that of iodized poppy seed oil among Indonesian schoolchildren. Am J Clin Nutr 84, 1208-1214.

55. Aboud FE, Bougma K, Lemma T, et al. (2017) Evaluation of the effects of iodized salt on the mental development of preschool-aged children: a cluster randomized trial in northern Ethiopia. Matern Child Nutr 13, e12322.

56. Bouhouch RR, Bouhouch S, Cherkaoui M, et al. (2014) Direct iodine supplementation of infants versus supplementation of their breastfeeding mothers: a double-blind, randomised, placebo-controlled trial. Lancet Diabetes Endocrinol 2, 197-209. 